Ethiopian Journal of Environmental Studies \& Management 9(Suppl. 2): 967 - 976, 2016.

ISSN:1998-0507

doi: http://dx.doi.org/10.4314/ejesm.v9i2.3S

Submitted: August 15, 2016

Accepted: December 14, 2016

\title{
ANALYSIS OF TRAIN SPEED PERFORMANCE ON NIGERIA RAILWAY CORPORATION LAGOS DISTRICT NARROW GAUGE TRACK
}

*DINA. A.0. AND RAJI, B.A.

Department of Geography Olabisi Onabanjo University Ago-Iwoye, Ogun State

\begin{abstract}
The study examines the railway speed performance on a $41 \mathrm{~km}$ mainline section of the $3505 \mathrm{~km}$ national network used for the Lagos Mass Transit Train service within the Lagos Administrative District of the Nigeria Railway Corporation (NRC). The study was necessary in order to establish improvements in track performance following recent rehabilitation of the entire $3505 \mathrm{~km}$ narrow gauge line in the country. Speed performance of train was measured using a vehicle tracking device placed inside a Kano bound train that continuously recorded the location and speed movement via Global Positioning System (GPS). The $41 \mathrm{~km}$ section used in the study was divided into $2 \mathrm{~km}$ subsection with number of curves and level crossing recorded against the average speed change using satellite image from Google Earth Pro. Result shows an average speed of $40 \mathrm{~km} / \mathrm{h}$ with peak speed performance around $53 \mathrm{~km} / \mathrm{h}$ while the least recorded was $20 \mathrm{~km} / \mathrm{h}$. Result from correlation analysis indicate curves and level crossings, the two speed inhibitors have a high positive correlation index of 0.862 implying both will likely occur closely. In terms of causes changes observed in train speed, the regression analysis further indicates the two independent variables Level crossing and Curves are not significant contributor to speed change of NRC trains. These two variables provide a marginal 9.5\% explanation of the observed average change in speed of NRC train within the section. The study made several useful suggestions as means of optimizing the capacity of the line section.
\end{abstract}

Key Words: Train Speed Performance Narrow Gauge Lagos Nigeria.

\section{Introduction}

The evolution of railway technology, network and service development has been quite different across the globe. While industrialized countries such as Britain, United State of America, China, Australia, Japan etc have over time improved the quality and coverage of rail service, developing countries in Africa and Nigeria in particular continue to grapple with many developmental challenges of rail technology. Presently, the need for highly efficient means of transportation besides road and air travel to cater for increasing dependence on public transportation is one issue that cuts across all industrialized and developing countries due to effects of rapid urbanization. To this end, owing to the attributes of railways in terms of carriage capacity and efficiency on one hand, on the other hand, progress in motive power, 
speed capabilities of trains now exceeds $400 \mathrm{~km} / \mathrm{h}$ making trains further attractive in terms of service quality. The Transport Research Board (TRB) in 2003 notes particularly that train speed today can now compete favorably with other modes of transport for both intra-city and intercity movements.

Speed is of central importance in railway research and management for several reasons; foremost is that it is a basic condition for the allocation of railway resources, an index set for the evaluation of track usage (Zhang et al., 2011) a major determinant of rail line capacity. In other words, train speed plays a major role in operational efficiency and its competitiveness with other modes available. Secondly it is a crucial aspect of railway safety management. As speed of trains continues to increase the level of threat it poses to track integrity increases with concomitant effect on train operation, safety and ride comfort (Wang et al., 2014). A National Transport Safety Board (NTSB) news leaflet in May 2015 on recent the AMTRAK intercity passenger train accident in Philadelphia USA suggest the derailment was caused by over speeding on a track curve. The Nigerian case however transcends beyond the foregoing, improving railway speed and coverage may be central to a sustainable national transportation planning effort by government. The desire for an integrated and efficient intermodal transport system can only be feasible if the country's railways compete favorably in terms of speed with other transport modes in the country.

Unfortunately railway system in Nigeria is under developed and inefficient (Odeleye, 2000). Since railway management in the country is vertically integrated in structure with government having the sole right to plan, build and operate rail service based on the 1955 railway act (Odeleye, 2015), development within the sector was subject to vagaries of government attitude. The technical problems associated with railway development in Nigeria have been adequately captured in literature in the work of Odeleye (2000); Adesanya (2002); Ademiluyi and Dina (2011) to include worn our infrastructure and rolling stock, lack of spare parts, high track gradient, sharp curves, track buckling. Odeleye (2000) observed these problems led to the poor speed performance of NRC trains limiting their speed to about $20 \mathrm{~km} / \mathrm{h}$.

Interestingly, the systematic adoption of $1435 \mathrm{~mm}$ (standard) gauge by most developed countries that began from 1937 (based on UIC recommendation) was principally born out of the need for railways to operate safely at higher speed. The successful impact of this transition around the world today has therefore consistently raised questions about the relevance of the existing meter gauge which currently dominates Nigeria's rail network. In a contrasting view, Yuasong (2003) observed that there may be a popular misapprehension that narrow gauge railway is slow, badquality and a waste of resource. He noted Japan one of the forerunner of modern train technology has about $23,219 \mathrm{~km}$ narrow gauge rail track, this also make up $87.6 \%$ of the total business mileage with goods carrying capacity exceeding 20 million tons and speed topping $130 \mathrm{~km} / \mathrm{h}$. Australia's Queensland narrow gauge line speed tops at $165 \mathrm{~km} / \mathrm{h}$. In Africa for instance, narrow gauge railway tracks 
from Abidjan to Niger was also observed to have reached a top speed of $160 \mathrm{~km} / \mathrm{h}$ in one among many experiments that demonstrates narrow gauge tracks having high speed capability (Yuasong, 2003).

Scholars have indeed associated several positive attributes with the increasing speed capability of trains. The deployment of high-speed trains has been associated with emissions reductions (Akerman, 2011). It is also related to potential modal shift to rail from air and road mode (Dobruszkes, 2011; Fu et al., 2012). High speed trains must also consider a wider geographic area for optimal operations (Maetinez et al., 2012), such service is regarded as being most competitive when the city-pair roughly 150 to 300 miles apart (TRB 2003).

In view of the facts emanating from the foregoing and following the recent completion of the first phase of government intervention in resuscitating the moribund railway sector in Nigeria, the entire $3,505 \mathrm{~km}$ network of $1067 \mathrm{~mm}$ narrow gauge line is now operational. Rehabilitation work is expected to have corrected most of the problems associated with the country's track work earlier discussed in this report. In further view of the huge investments expended on new track infrastructure and rolling stock and the new light shed on speed capabilities of narrow gaugelines, improvement in speed performance of NRC trains is naturally anticipated. Indeed certain questions becomes pertinent and begging at this juncture. First, if there is any significant improvement in NRC train speed? What is the likely contribution of speed inhibitors such as track curve and level crossings to the speed pattern of trains? These questions among other issues makes an analytical study on rail speed using the Lagos district mainline the busiest section of the entire NRC rail network to be compelling.

\section{Aim and objectives of study}

The aim of the study is to analysis of train speed performance on Nigeria railway corporation Lagos District narrow gauge track.

The specific objectives outlined for the study include;

i. Measure the speed performance of NRC trains along the district mainline.

ii. Examine the association between speed inhibitors along the track.

iii. Examine the effect of track curves and level crossings on train speed

iv. Provide relevant suggestions on the relevance of the observed train speed performance for NRC operations.

\section{Conceptual Framework}

The study is anchored on speed Management concept. Speed and movement has been central to man's activities from time in memorial, it none the less continues to play an increasing role in the sustenance of the present world order. Objects in motion often have variations in speed in a period of time, conceptualizing an average for objects with variation in speed is therefore defined as the distance travelled by the object divided by the duration of the interval. In physics, the SI unit of speed is the metre per second $(\mathrm{m} / \mathrm{s})$, but the most common unit of speed in everyday usage is the kilometre per hour $(\mathrm{km} / \mathrm{h})$.

In transport research and planning, speed capabilities of vehicles are of central importance. The need to constantly improve capacity and efficiency of transport infrastructures 
around the world due to the dynamic nature of demand being placed on them has brought about the need to safely operate at higher speed. As access to transport service continues to increase, technological development has constantly reshaped all mechanized modes in terms of their speed capability. Hence trains which for example debuted with speed just above $20 \mathrm{~km} / \mathrm{h}$ now have certain type of trains with speed around $500 \mathrm{~km} / \mathrm{h}$. Speed control and management also features prominently in the safety regulation in transport. Limiting and controlling speed of vehicles particularly on trains is critical to safe operation and ridership. Where such standards are violated accidents become inevitable. Such is the case of the AMTRAK train accident in Philadelphia where the intercity train derailed due to excessive speed within a track curve. In other words irrespective of mode transport planners and administrators will continue show concern for vehicle sped either high or low.

\section{Methods}

\section{Research Design}

The study is designed as a field experiment using information from train movement within a section of the NRC Western Line (Lagos District) starting from Iddo in mainland Lagos to Ifo Ogun State Nigeria. In the absence of speed record of train from NRC, it was necessary to map train speed performance. This was achieved using a vehicle tracking device, a mobile telematic device that continuously records the location and speed movement through Global Positioning System (GPS). The system is integrated with GPRS technology for the transmission of recorded information back to a remote computer at a base station. The device operates on mobile telephone technology and is propped to store information on its internal memory in the event of a loss of GSM signal and later relay such to the remote base station. Several important configuration was necessary to manage the volume of information to be received since this report was part of a larger study on the NRC western line. The device was set to continuously communicate with the remote computer in event of any of the following; (i) when the train comes to a halt or resumes from such; (ii) when there is a major change in the heading of the train; (iii) when speed exceeds $40 \mathrm{~km} / \mathrm{h}$ or drops below $20 \mathrm{~km} / \mathrm{h}$ respectively. A back up power bank was attached to the device to extend it powers beyond 24 hour if the need arose.

\section{Research Process}

The tracking device was placed inside the moving train with adequate signal for most of the duration of a train trip between Lagos and Kano. These information were later retrieved from the remote base station, which proved accurate in location and speed reports. In order to retrieve track information Google Earth application proved adequate. The $41 \mathrm{~km}$ stretch between Iddo terminus and Ifo junction was divided into $2 \mathrm{~km}$ subsection. Thereafter the number of curves and level crossing within every $2 \mathrm{~km}$ was recorded and tabulated against the average change in speed within each section. The outcome was a set of data that could be used to establish relationship between speed change, presence of level crossing and track curves. 


\section{Analytical Technique}

Both descriptive and inferential has been adopted for use in this publication. Descriptive statistics such as graph and tables were used to present the array of speed data from NRC train within Lagos district. Inferential statistical methods such as multiple regression was adopted in investigating the influence of rail track alignment and level crossing on speed performance along the mainline. The regression model used in analysis is given by the equation;

$\mathrm{y}=\mathrm{a}+\mathrm{b}_{1} \mathrm{x}_{1}+\mathrm{b}_{2} \mathrm{x}_{2}+\mathrm{e}$ where;

$\mathrm{y}=$ dependent variable average change in speed within sections of Lagos district mainline

$\mathrm{a}=$ regression constant

$\mathrm{b}=$ criterion of independent variable

$\mathrm{x}_{1}=$ independent variable which is number of level crossings at each section of track $\mathrm{x}_{2}=$ independent variable which is number of curves at each section of the track

$\mathrm{e}=$ error term of the regression equation

\section{Result and Discussion}

The train started from rest at the Iddo station on the mainland of Lagos State at exactly 12:05, five minutes behind the scheduled departure time. The train accelerated to $36 \mathrm{~km} / \mathrm{h}$ within $2 \mathrm{~km}$ of travel before a slight drop in speed (See Figure 1 below). Thereafter there was a more rapid increase in speed to $50 \mathrm{~km} / \mathrm{h}$, thereafter series of deceleration and acceleration produced several sequence of waves like pattern of graph with several peaks.

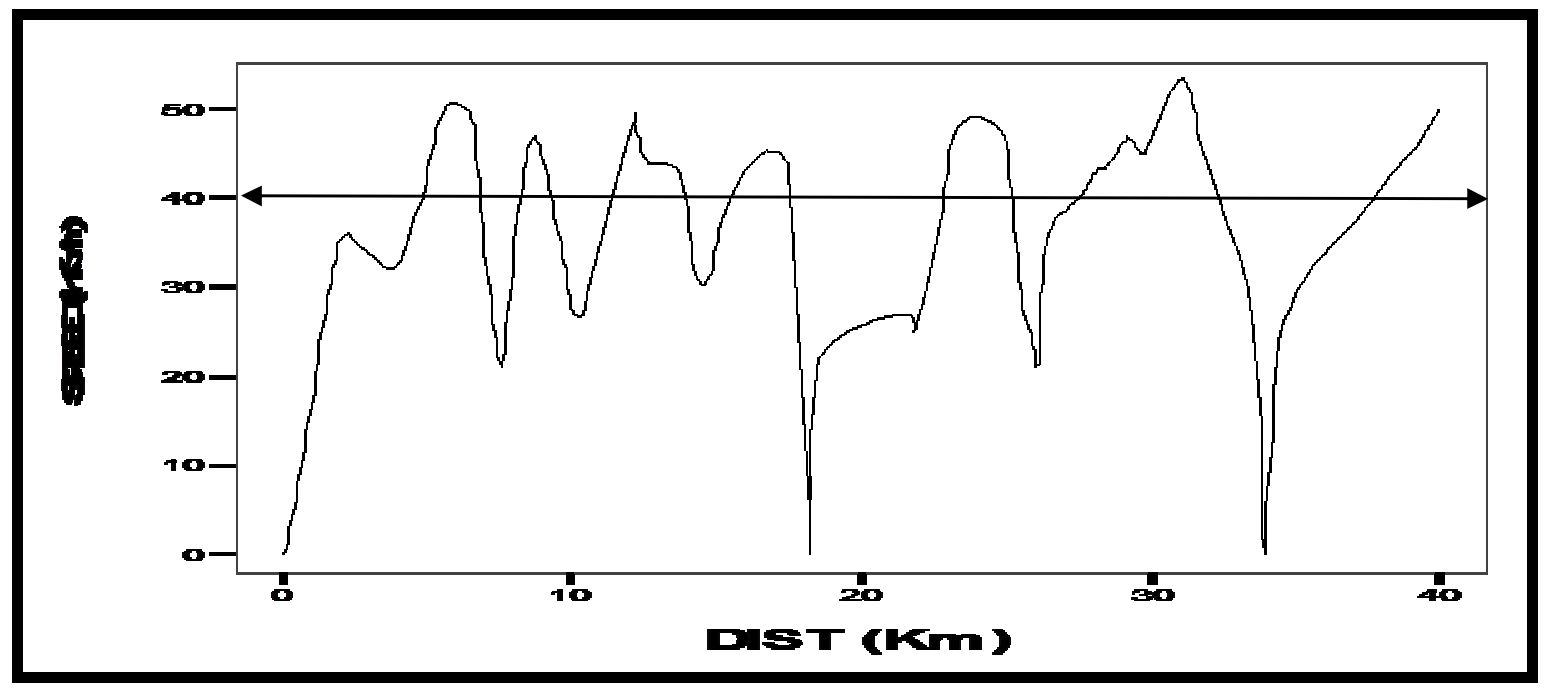

Figure 1: Showing graph of speed log graph of NRC train within Lagos district

There are two instances when the train halted around kilometer18 at the Agege train station and kilometer 33 at Ijoko station with a dwell time of 5 and 6 minutes respectively before resuming the trip. Peak speed performance within the section of the line is put at $53 \mathrm{~km} / \mathrm{h}$ while the lowest speed performance was $21 \mathrm{~km} / \mathrm{h}$. The average speed of the train within the $41 \mathrm{~km}$ section under review is 
approximately $40 \mathrm{~km} / \mathrm{h}$. The average speed was adopted as the train speed benchmark or minimum threshold along the track. The total journey time for the $41 \mathrm{~km}$ trip including the dwell time at the two stations is exactly 1:08minutes. Inputting the average speed on the graph of the actual speed (figure 1) thus reveals the areas where speed is lower than the minimum threshold of $40 \mathrm{~km} / \mathrm{h}$.

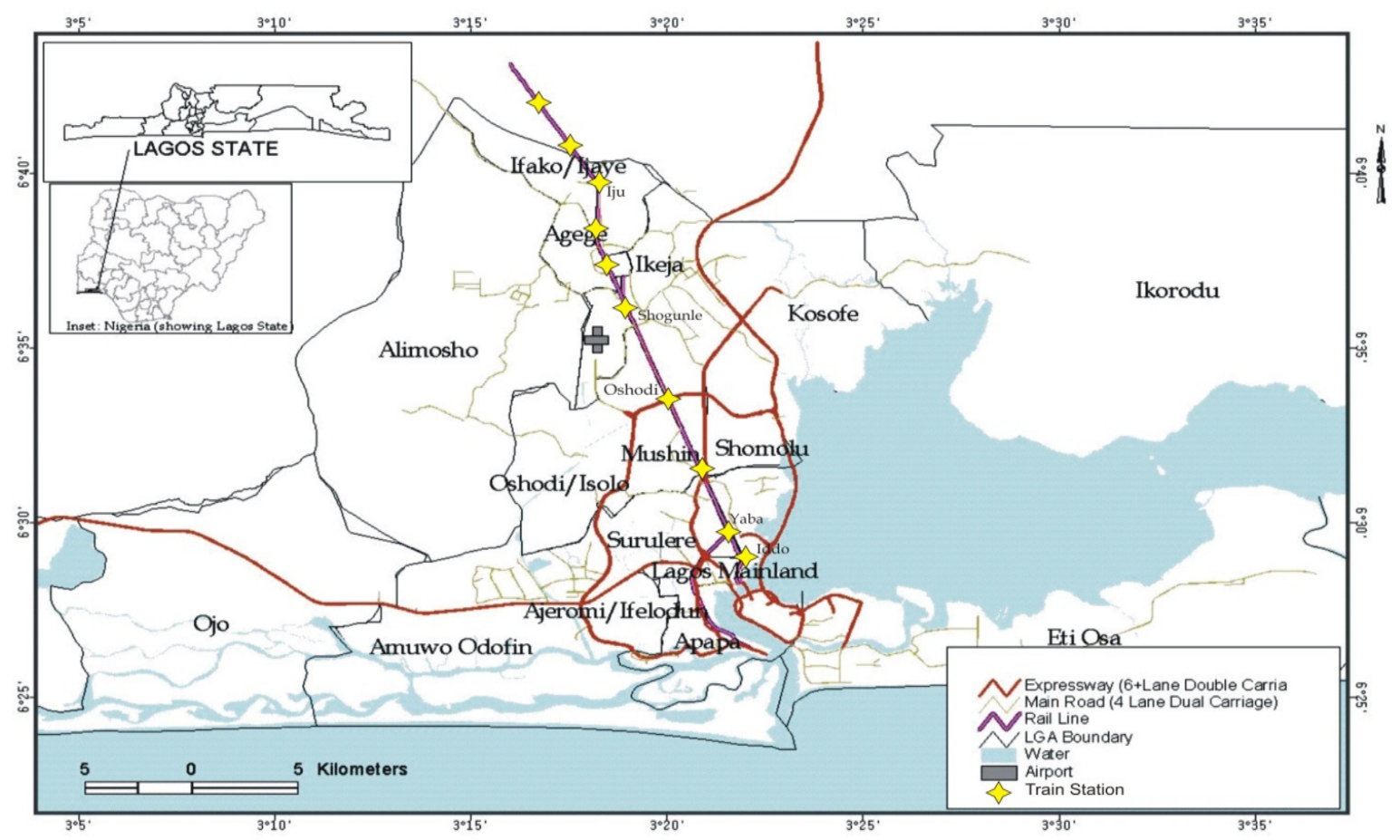

Figure 2: Showing NRC Western District rail line and stations

Source: Adapted from Okanlawon, (2007)

The current rehabilitation work on this section has improved speed performance on this section from the $20 \mathrm{~km} / \mathrm{h}$ observed by Odeleye (2000) to and $40 \mathrm{~km} / \mathrm{h}$ average representing at least a $100 \%$ improvement. However, this is still a far cry from the speed performance of observed in many countries with advanced rail network and $130 \mathrm{~km} / \mathrm{h}$ suggested by Yuasong (2003). There are other factors to note. Train operations at higher speed needs longer breaking distance and also affects line capacity (TRB, 2003) it is unclear if this is the case or other track issues is responsible for this. It is important to indentify the pattern of high and low speed performance of trains on the track.

Track Structure and Speed Performance

The presence of level crossing and curves is known to have a direct effect on the operating speed of railways (Ghawale et al., 2015; Choi and Shin, 2015). It is thus important to verify if the changes observed in speed along the tracks can be associated with its physical attributes, this requires further analysis. 
Table 1: Showing relationship between speed and track attributes

\begin{tabular}{|l|l|l|l|}
\hline & Level crossing & Curve & Average speed change \\
\hline Level Crossing & 1 & $0.862(* *)$ & $0.408(*)$ \\
Curve & & 1 & $0.421(*)$ \\
Average speed change & & & 1 \\
\hline
\end{tabular}

*significant at $0.05, * *$ significant at 0.01

The relationship between the average change in speed and track attributes shows some interesting result. There is a strong positive relationship between the occurrence of curves and level crossing on the NRC mainline within the Lagos district (Table 1). This implies that the location of curves and level crossing, two speed inhibitors occur closely and such arrangement is not by chance. The relationship between speed changes and level crossing occurrence low but also positive (0.408) we suspect level crossing has little bearing on speed change. Interestingly speed change has a positive and significant relationship with curve occurrence on the line (0.421) implying both exert similar effect on each other. This simply means that presence of curves along the track does not impede train speed. Regressing speed change of trains against number of curves and level crossing is an attempt to establish the influence of number of curves and level crossings along the track on the changes in speed of the train.

Table 2: Model Summary for Regression

\begin{tabular}{lllccc}
\hline Variables & $\begin{array}{l}\text { Variable } \\
\text { Acronym }\end{array}$ & $\begin{array}{l}\text { UnStd. Reg. } \\
\text { Coeff }\end{array}$ & $\begin{array}{l}\text { Std. Reg. } \\
\text { Coeff }\end{array}$ & Std. Error & T-Value \\
\hline (Level Crossing) $\mathrm{x}_{1}$ & $\mathrm{LC}$ & 2.111 & 0.178 & 4.969 & 0.425 \\
(Curve) $\mathrm{x}_{2}$ & $\mathrm{C}$ & 2.812 & 0.267 & 4.416 & 0.637 \\
Constant & -3.354 & & & & \\
Multiple R & 0.430 & & & & \\
Model adjusted R & & & & \\
Model F-Ratio & 0.0 .95 & & & & \\
$\mathrm{~N}$ & 2.045 & & & & \\
*significance $=0.05$ Level. & & & &
\end{tabular}

The result of the regression analysis using the least square method is presented in table 2 . The multiple $\mathrm{R}$ which measures the strength of association between the dependent variable $\mathrm{Y}$ which is the average change in speed and all independent variables $\mathrm{x}_{1}$ and $\mathrm{x}_{2}$ level crossing and track curve respectively is 0.430 . This suggests that the number of crossing and curves along the track doesn't impede speed of the train. Thus, the more the level crossings and curves the more the speed recorded. The adjusted $\mathrm{R}^{2}$ of the model indicated that the contribution of the number of level crossing and curves along the train track within the NRC Lagos District is as low as $9.5 \%$. This shows that the number of level crossing and curves have little contribution to variation in the train speed. Thus $90.5 \%$ of the variations in speed are related to other factors not accounted in the model. This could have been responsible for the insignificance of 
number of level crossings and curves by the F-Ratio $(\mathrm{F}=2.045, \mathrm{p}<0.05$ as shown in the model in table 2). However, as far as the importance of the two variables is concerned, speed changes appear more sensitive to curves than Level-crossings. The standardized regression coefficient guarantees measured units of the independent variables are comparable when trying to adjudge relative importance to these independent variables (Oyesiku 1995). The standardized regression coefficient and tvalue posted for each variable are available in table 2 .

The research so far indicates an average speed performance of $40 \mathrm{~km} / \mathrm{h}$ on NRC mainline within the Lagos district. This is an indication of a near $100 \%$ improvement in the average speed of trains from $20 \mathrm{~km} / \mathrm{h}$ noted by Odeleye (2000), such improvement may partly influnce the poor service quality assessment of NRC trains reported by Agunloye and Oduwaye (2011). This improvement may be attributed to the track rehabilitation works and supply of brand new locomotives to the corporation. However, the speed capability of the General Electric Locomotives currently in use by NRC is pegged at $100 \mathrm{~km} / \mathrm{h}$, peak utility is therefore $50 \%$ of installed capacity. The inability to attain the optimum speed capacity of these trains made the study to consider curves and level crossings to be strong suspects. However result so far indicates both curves and level crossings are not significant predictors of speed changes observed along the Lagos mainline. Wang et al. (2014) notes track irregularity is one of main factors that directly limit the speed and quality of train operation in -increased-speed and high speed railway. It may be necessary to consider this in other studies. This was reechoed by Zhi-Chen et al. (2014) who observed vibration of the vehicle and track components due to track irregularities which increases as the train's speed increases. Changes in observed speed of NRC trains may be a direct response to track irregularity rather than curves and level crossings which the study suggested for further study.

\section{Recommendation}

This study recommends further study to investigate the contribution of track irregularity on speed variance. Such investigation may be directed at track integrity or the effect of human encroachment on railway right of way. Erection of fence along the rail track to prevent encroachment by pedestrians and street traders. Furthermore, train speed and track capacity within the section can be greatly enhanced if it is made a double track and its embankment raised. The single track system negatively affects train speed due to conflicting traffic. Lastly, the management of NRC should migrate from the fixed block signal system to computerized signal control for greater efficiency of train movement. Finally, the marginal time difference between expected speed on standard gauge lines within the district suggest effort be made to expand the existing narrow gauge network as a way to improve the accessibility to railway service within the Lagos metropolis.

\section{Conclusion}

This study concludes that the changes observed in speed of NRC trains along the Lagos district mainline is not related to the occurrence of curves and level 
crossings on it. The $50 \mathrm{~km} / \mathrm{h}$ peak speed observed in this study is half installed capacity of the new 22 and 23 class General Electric locomotives currently in use by the corporation. The observed speed performance of this study may however be within the speed threshold recommend by Transport Cooperative and Research Programme in 2003 on transit capacity and quality of service. This manual recommends a threshold speed of $50 \mathrm{~km} / \mathrm{h}$ as a means to optimize line capacity for intra-city train operations. Most metro train service across the globe however have their operating speed pegged between 40$75 \mathrm{~km} / \mathrm{h}$ due to safety reason. In view of this, narrow gauge train service could still be relevant to the mass transit needs within the metropolitan and suburb areas of Lagos which is in an urgent need of an alternative mass transit mode. Higher speed performance will however be desirable to improve the service quality of intercity train service in Nigeria. This is in line with the observations of Maetinez et al. (2012) and TRB 2003 which require higher speed for long distance train trips.

\section{References}

Ademiluyi, I.A. and Dina, A.O. (2011). The Millennium Development Goals and the Sustainable Future for Nigeria's Urban Environment: A Railway Strategy. Journal of Human Ecology, 33(3): 203-209.

Adesanya, A. (2002). Declining fortunes of rail transport in Nigeria, Response and Direction of Policy. NISER Monograph Series No.8, 2002.

Agunloye, O.O. and Oduwaye, L. (2011). Paper Factors influencing the quality of rail transport services in metropolitan Lagos. Journal of Geography and Regional Planning, 4(2): 98-103. http://www.academicjournals.org/J GRP ISSN 2070-1845.

Akerman, J. (2011). The role of highspeed rail in mitigating climate change - The Swedish case

Europabanan from a life cycle perspective. Transportation Research, 16(3):208-217. doi.10.1016/j.trd.2010.12.004

Choi, Y.S. and Shin, B.S. (2015). Critical speed of high-speed trains considering wheel-rail contact.

Journal of Mechanical Science and Technology, 29(11): 45934600

Fu, X., Zhang, A. and Lei, Z. (2012) Will China's airline industry survive the entry of high-speed rail.

Research in Transportation Economics, 35(1): 13-25.

Ghawale, A.R., Gawande, S.K. and Rakhonde, B.S. (2015). Dynamic structure of track geometry. International Journal of Engineering Sciences and Research Technology, 4(2): 325-329.

Odeleye, J.A. (2000). Public-private participation to rescue railway development in Nigeria. Japan Railway and Transport Review Journal, 23: 42-49 page 104-111.

Odeleye, J.A. (2015). The Challenges to Competitive Rail Transport System in Nigeria. A paper delivered at National Railway Conference, Sheraton Hotel and Towers Abuja 10/31/2015

Nigeria Railway Corporation, (2013). Back on track. An NRC Television 
Documentary on Railway Rehabilitation in Nigeria.

Ortega, E., Lopez, E. and Manzon, A. (2012). Territorial cohesion impacts of high speed rail at different planning levels. Journal of Transport Geography, 24: 130-141.

Oyesiku, O.O. (1995). Understanding multiple regression analysis. Higher Education Books Series HEBS ISBN 97832259-3-4.

Sanchez-Mateos H. M. and Givoni M., (2012). Changes in accessibility that might result from a new HighSpeed Rail (HSR) line in the UK. Journal of Transport Geography, 25:105-114.

Transportation Research Board (2003). Transit capacity and quality of service manual. second edition. TCRP Report 100, TRB, Washington.

Transportation Research Board (2015). Preliminary investigation press release on AMTRAK train accident. http://www.ntsb.gov/news/pressreleases/Pages/PR20150520.aspx Yuasong, T. (2003). A study on the development of East Asia narrow gauge railways. Proceedings of the Eastern Asia Society for Transportation Studies, Vol.4, October, 2003

Wang, Z. and Song, Y. (2014). Relation between track irregularity of speedincreased railway and dynamic speed limits through simulation. The Open Mechanical Engineering Journal, 8: 197-200.

Zhang, J., Han, B. and Nie, L. (2011). Research on capacity calculation and assessment framework for Chinese high speed railway based on UIC406. Journal of System and Management Sciences, 1(6): 5975. 